\title{
Mobility after Heart Surgery: What Are Influential
}

\section{Factors?}

Gabriela Lago Rosier ${ }^{1}$, Gleide Glícia Gama Lordello ${ }^{1}$, Marcela Araujo de Moura ${ }^{1}$, Larissa Santana Correia ${ }^{1}$, Luana Lais Silva Polte ${ }^{1}$, Giulliano Gardenghi ${ }^{2}$, Luis Cláudio Correia ${ }^{1}$, Patricia Alcântara Doval de Carvalho Viana $^{1}$

1.Escola Bahiana de Medicina e Saúde Pública, Salvador 40290-000, Brasil

2. Hospital ENCORE, Goiás 74930-390, Brasil

\begin{abstract}
Objective: To analyze postoperative mobility after cardiac surgery. Methods: Observational study in patients, aged $\geq 18$ years, undergoing myocardial revascularization and/or valvular heart surgery, hospitalized in a Brazil hospital. The data collection took place between April 2016 and March 2017. On admission to the ward, patients received a calibrated pedometer. They were asked to use the device during five consecutive days, yet only three days of full use were analyzed. Results: Analyzed were data of 87 individuals with mean age of $58.70 \pm 12.59$ years, $52(59.8 \%)$ of them were males. Regarding surgery, 53 (60.9\%) underwent myocardial revascularization. The median number of steps was 738 (185-1,557), which showed a weak and inverse correlation with the length of stay in the intensive care unit $(\mathrm{r}=-0.3 / p=0.02)$, however, it was not statistically significant when related to clinical and surgical data. Male patients had a better mobility when compared to patients of the female sex $(p=0.04)$. Conclusions: Individuals who had a longer stay in the intensive care unit, as well as females, had a lower mobility in the ward. The mobility did not show a relation with intra- and postoperative factors.
\end{abstract}

Key words: Cardiac surgery, physiotherapy, ambulation.

\section{Introduction}

Cardiac surgeries are highly complex procedures that generate a need for intensive care by a multiprofessional team in the postoperative period [1]. To this end, patients are transferred to an ICU (intensive care unit), where immobility and inactivity are common. This could, in association with preoperative and intraoperative risk factors, generate organic changes in physiological mechanisms, as well as systems of the human body [2, 3].

It could be of importance to leave the bed at the earliest opportunity to do physical exercises, whether spontaneous or supervised, as exercising produces benefits related to cardiovascular conditioning, and

Corresponding author: Gabriela Lago Rosier. Specialist physiotherapist of Hospital Santa Izabel, participant of search group of cardiovascular and respiratory physiotherapy of Bahiana (GEPFIR), research fields: physiotherapy and cardiovascular disease. reduces morbidity and pulmonary complications [4]. To quantify physical activities, the pedometer is an instrument frequently used in the literature, a tool with a mechanical sensor that counts vertical oscillations of the body and translates them into a number of steps $[5,6]$.

The number of steps is used as the numerical representation of physical activity level of population groups [6-8]. This activity expresses the level of mobility, which, according to the ICF (international classification of functioning, disability and health) [9], consists of movements from body position changes to displacement with ambulation. In this context, due to the absence of a pre-established reference value to be used as a therapeutic goal or recommendation for this at-risk population, the evaluation of the level of mobility in the hospital phase of cardiac rehabilitation becomes fundamental for physiotherapeutic practice. 
Therefore, in order to set goals for recovery, and offer better physiotherapeutic care, we designed this study to analyze the mobility in the post-cardiac surgery period.

\section{Materials and Methods}

\subsection{Study Design}

A cross-sectional observational study was carried out in a referral hospital for cardiology in the city of Salvador, Bahia, Brazil, where data collection started in April 2016 and completed in March 2017. Selected were hospitalized patients with MR (myocardial revascularization) and/or heart valve surgery scheduled. Patients were of both sexes, aged $\geq 18$ years (lower age for be admitted in the intensive care unit). Excluded were those with difficulties in understanding the activities involved in the research, or with dependent ambulation. Regarding the type of surgery, in the case of related procedures, the patients were allocated to the group of the main surgery in question.

In the preoperative period, individuals were invited to participate in the study, and sign the informed consent form. Subsequently, participants were asked to complete the International Physical Activity Questionnaire (IPAQ—-short version) [10]. Then, according to the results, participants were classified as active, irregularly active, or sedentary, according to the time spent in physical activities before hospitalization. Clinical- and surgical information was collected through the medical records and transferred to the data collection form.

On admission to the ward, participants received a calibrated and sealed pedometer (ONMROM 320i), and were instructed to fasten it to their clothes at hip height, only to remove it to sleep at night or when taking a shower. The period of use of the device was five days, as described in Fig. 1, and, only the data of three days of full use were counted. Researchers visited each individual on a daily basis, to check the device, and to mensure optimal operation.

The sample power was obtained through the WinPepi calculator (publichealth.jbpub.com/book/gerstman/winpepi.cfm). The Etcetra command was selected with $\mathrm{n}=87$ people, to obtain a correlation coefficient of 0.4 , and a significance level of $5 \%$, resulting in a power of $97.3 \%$.

\subsection{Statistics Analysis}

The SPSS (statistical package for social sciences), version 14.0 for Windows, was used to create the database, and the descriptive and inferential analysis. The normality of the variables was tested by using descriptive statistical analysis. The Mann-Whitney test was used to compare the medians of the number of steps between the type of surgery and type of sex. The difference between the medians of the levels of physical activity, was obtained through the Kruskal-Wallis test. The Spearman's correlation coefficient was used to analyze the correlations between age, BMI (body mass index), ICU time, drain, MV (mechanical ventilation), and bed restriction, with the number of steps. The data of three days of use of the device were compared by using the Friedman test, with post hoc analysis done by dividing the $p$-value of the Wilcoxon test by the number of comparisons. The level of significance was $5 \%$.

\begin{tabular}{|c|c|c|c|c|}
\hline $\mathbf{1}$ & $\mathbf{2}$ & $\mathbf{3}$ & $\mathbf{4}$ & $\mathbf{5}$ \\
\hline $\begin{array}{c}\text { ICU Discharge } \\
\text { Pedometer }\end{array}$ & Ward & Ward & Ward & Ward \\
\hline
\end{tabular}

Fig. 1 Pedometer usage diagram of individuals in the post-cardiac surgery period Salvador-BA, 2017. 


\subsection{Ethics Statement}

The study has been approved by the Ethics Committee on Research in Human Beings of the Santa Izabel Hospital, under the CAAE: 55241616.6.0000.5520, in accordance with Resolution 466/12.

\section{Results}

The sample was composed according to information as depicted in Fig. 2, resulting in $\mathrm{n}=87$ individuals.
The mean age was $58.70 \pm 12.59$ years, 52 (59.8\%) of them were males, with a mean BMI of $25.97 \pm 3.86$ $\mathrm{kg} / \mathrm{m}^{2}$. Regarding surgery, 53 (60.9\%) underwent MR, while 34 (39.1\%) underwent heart valve surgery. The median of the total number of steps was 738 (185-1,557). According to the IPAQ questionnaire data, 51 (59.3\%) were considered active, 26 (30.2\%) were irregularly active and 9 (10.5\%) were sedentary. Clinical- and post surgical data are described in Table 1.
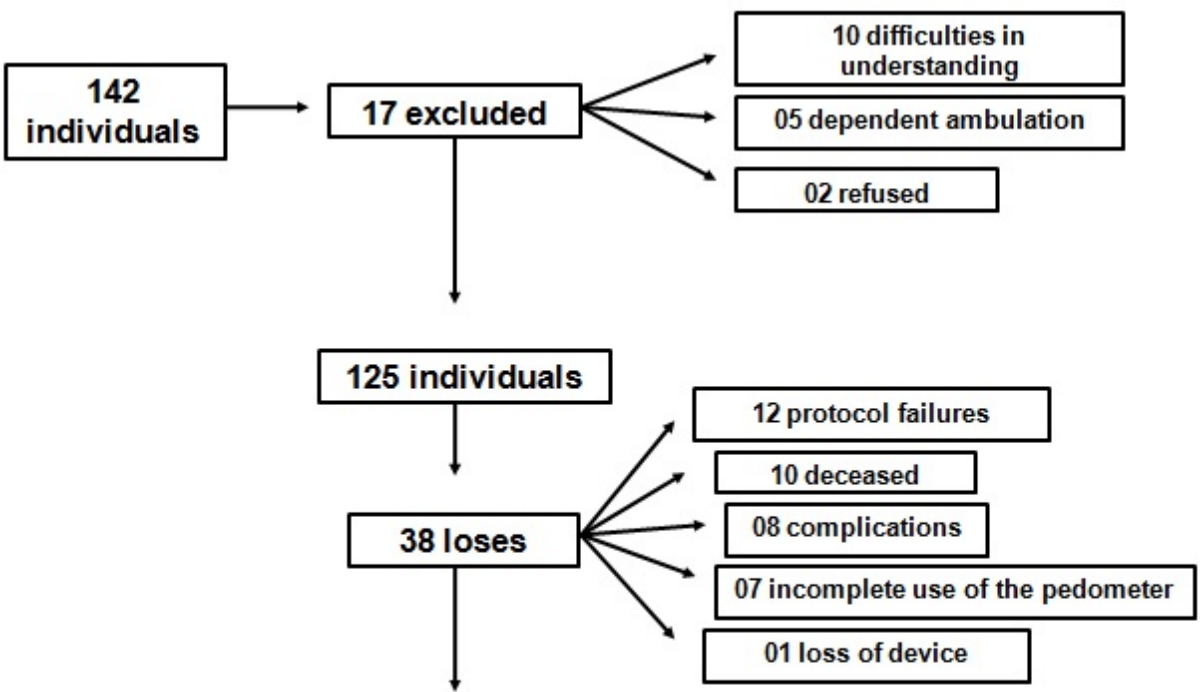

\section{TOTAL: 87}

Fig. 2 Flowchart of sample composition of individuals in the post-cardiac surgery period. Salvador-Bahia, 2017.

Table 1 Clinical and postoperative data of the individuals in the post-cardiac surgery period. Salvador-BA, 2017.

\begin{tabular}{ll}
\hline Analyzed variable & Mean \pm SD \\
\hline Age (years) & $58.70 \pm 12.59$ \\
BMI $\left(\mathrm{kg} / \mathrm{m}^{2}\right)$ & $25.97 \pm 3.86$ \\
Bed restriction (hours) & $46.74 \pm 19.78$ \\
\hline & Median (IQ) \\
\hline MV time (hours) & $5.08(3.50-8.54)$ \\
Drain Time (hours) & $28.40(24.66-37.25)$ \\
ICU time (days) & $02(2-3)$ \\
\hline & Mean \pm SD / Median (IQ) \\
\hline Number of steps & $1,108.45 \pm 1,264.19 / 738(185-1557)$ \\
Sex & $n(\%)$ \\
Male & $52(59.8 \%)$ \\
Type of surgery & \\
Myocardial revascularization & $53(60.9 \%)$ \\
Valvular heart surgery & $34(39.1 \%)$ \\
\hline
\end{tabular}

$\mathrm{BMI}$ = body mass index; $\mathrm{MV}=$ mechanical ventilation; $\mathrm{ICU}$ = intensive care unit. 
When comparing the data of the three days of use of the device, we identified that the number of steps is greater the longer the stay in the hospital. With a statistically significant relation ( $p=0.014$ ) in the variation of 205.36 steps, between the first and third day of using the pedometer, (Fig. 3).

In the comparison between the medians of the number of steps between the sexes, it was found that patients of the male sex have a greater mobility when compared to those of the female sex $(p=0.04)$. While comparing the types of surgery, no statistical difference was found. Although the sedentary individuals obtained a higher median of steps, no difference was found between physical activity levels and mobility ( $p=0.27)$ (Table 2).

Mobility, represented by the number of steps, did not show a correlation with age $(p=0.31), \operatorname{BMI}(p=0.36)$, time of $\mathrm{MV}(p=0.11)$, restriction to bed $(p=0.40)$ or

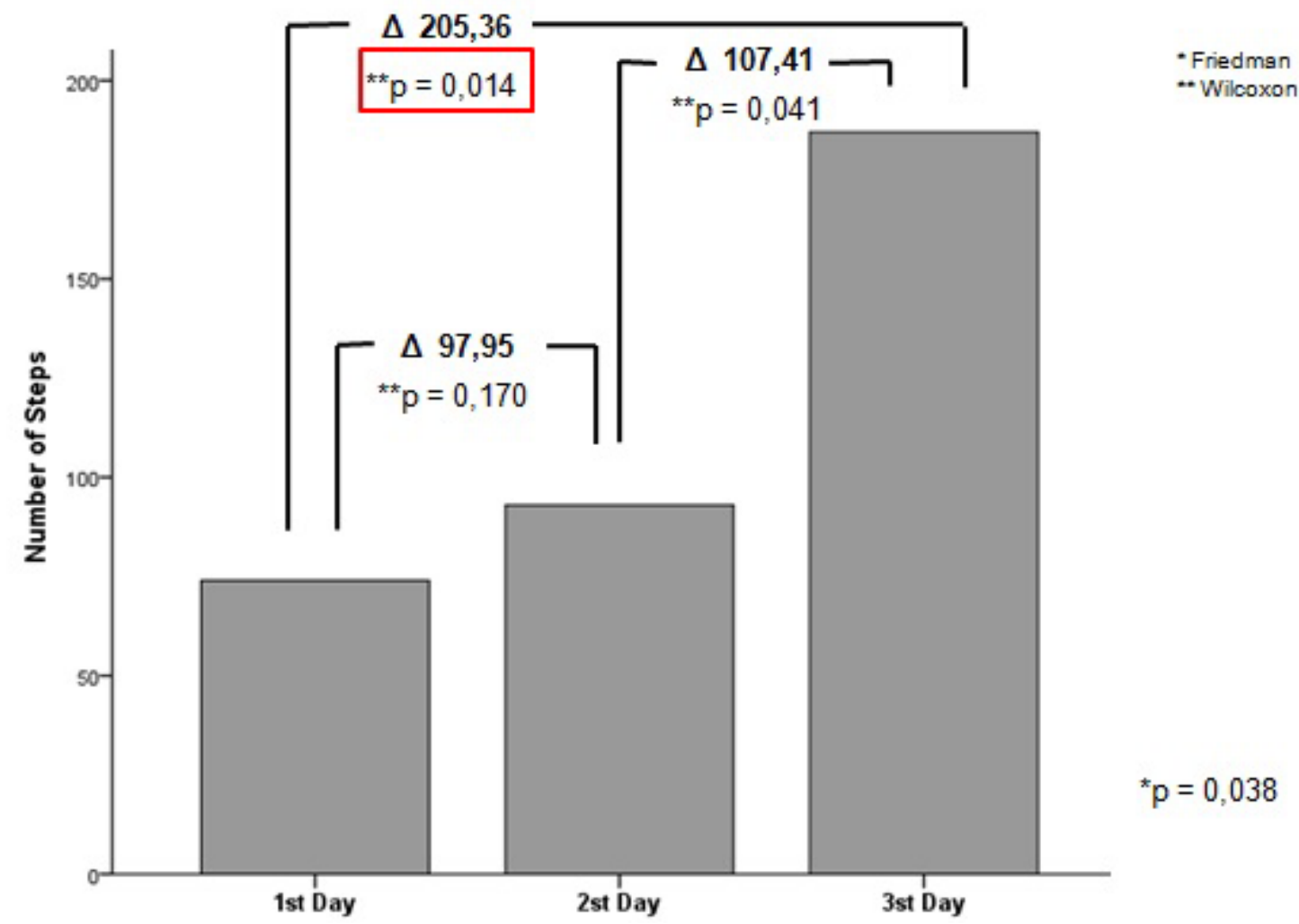

Fig. 3 Median comparison between days of pedometer use in the post-cardiac surgery period. Salvador-Bahia, 2017.

Table 2 Median comparison of the number of steps between sex, type of surgery and level of physical activity in individuals in the post-cardiac surgery period. Salvador-BA, 2017.

\begin{tabular}{lll}
\hline Sex & Number of steps & $p$ \\
\hline Female & $478(134-841)$ & $0.04^{*}$ \\
Male & $946(235.25-1,733)$ & \\
\hline Type of surgery & $478(176-1,799)$ & $0.45^{*}$ \\
\hline Myocardial revascularization & $841(303.75-1,438.75)$ & \\
Heart valve surgery & & \\
\hline Level of physical activity & $765(299-1,678)$ & $0.27^{* *}$ \\
\hline Active & $456(128-1,371.5)$ & \\
Regularly active & $1,298(54-2,369)$ & \\
Sedentary & &
\end{tabular}

* Mann-Whitney.

** Kruskal-Wallis. 


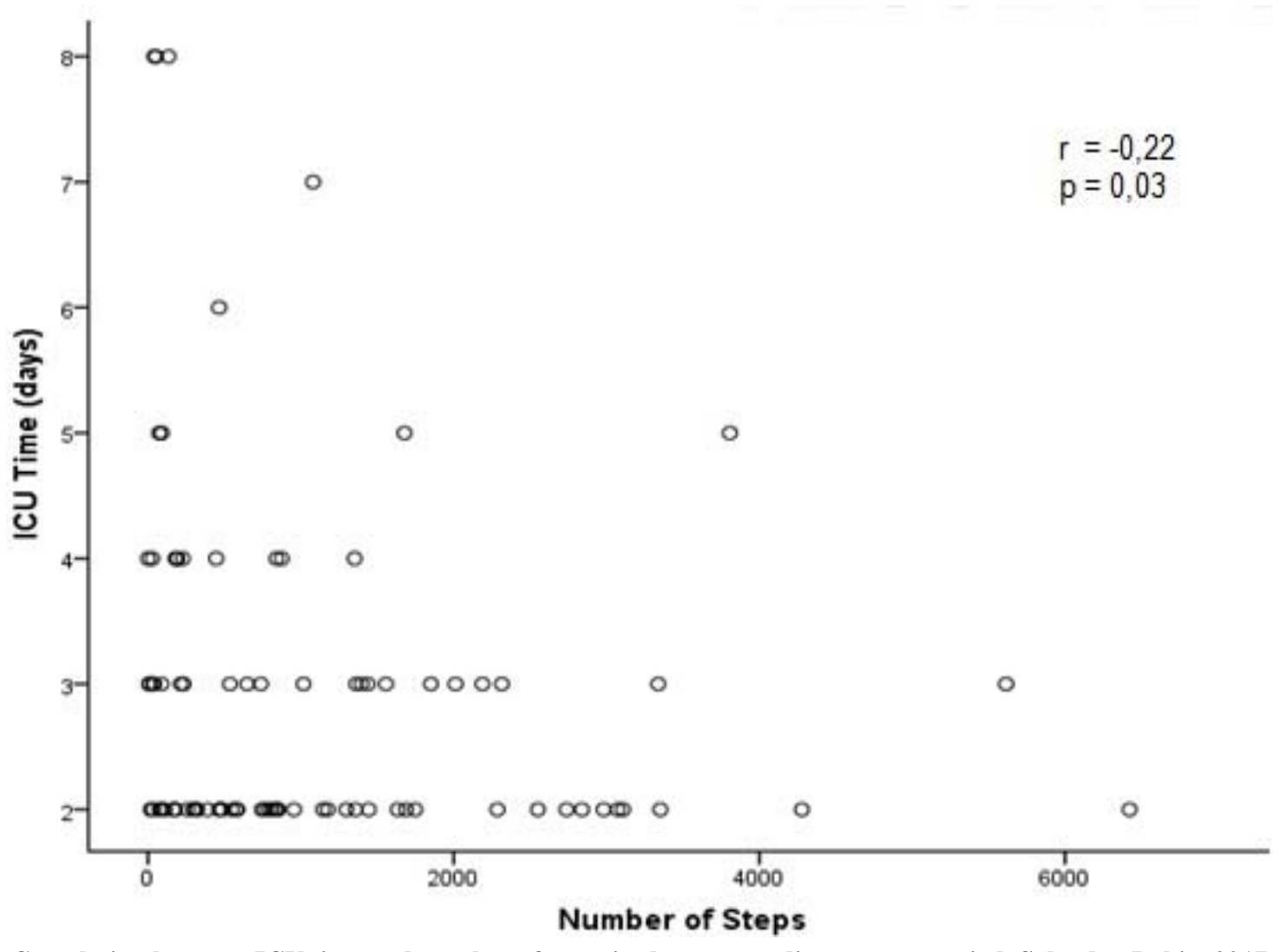

Fig. 4 Correlation between ICU time and number of steps in the post-cardiac surgery period. Salvador-Bahia, 2017.

drains $(p=0.87)$, and showed a weak and inverse relationship with the length of ICU stay $(\mathrm{r}=-0.3 / p=$ 0.02) (Fig. 4).

\section{Discussion}

Several studies validate the pedometer as a therapeutic tool, used as an incentive for independent physical activity, once the user receives visual feedback from the device [11-13]. In this research, the device was only used as an instrument to measure mobility, as it was delivered sealed and the participant did not have access to the recorded data. In this way, taking into account the lack of visual motivation and daily incentive and given the option by the researchers to perform any type of activity, rather than evaluating mobility, their data reveal the possibility and willingness to leave the bed.

The average number of steps found in this study was approximately 1,000 steps, a value lower than that shown by another author with a similar population [13].
In this study, the author describes an average of approximately five thousand steps, which may be explained by a higher number of evaluated days than selected for our research (five and three days, respectively). Both, in these case studies and in the other studies involving the number of steps in cardiopathic patients, the presence of large variations of this value is notorious and unanimous, demonstrating a heterogeneity of this population with respect to mobility.

The harmful effects of the ICU [3, 14-16] and, mainly, its functional repercussions on the patients are well described in the literature. As it is an intensive care unit, with potential limitations to leave the bed, such as continuous monitoring, presence of venous access and induction, and reduced physical space [17, 18], its users end up changing their functional independence, even without having limiting clinical factors. Thus, although the length of stay in the ICU was within the expected range [19, 20], we observed 
that the small number of individuals who remained in this unit for a longer time registered an evenly smaller number of steps in the ward.

In several studies, males presented better pedometer performance when compared to females [13, 21]. In a study performed in patients after cardiac surgery, the mean number of steps of men in five days was 3,380 steps, while in the female population, this number dropped to less than half [13]. Conform the previously described profile, in this sample, the female presented a smaller number of steps, although they were younger, with higher EF (ejection fraction), shorter ECC (extracorporeal circulation), less drainage and restrictions to the bed, factors that can represent lower postoperative complications.

Two authors, in different studies [22, 23], showed that, just as in this research, the daily average of free physical activity after discharge from the ICU was upward, representing an increase in the mobility already expected after hospitalization. Such mobility, according to the research findings, have not show a relation with the clinical or surgical factors of the cardiac procedure itself. In addition, although individuals that underwent heart valve surgery were younger, no difference between the ages and types of surgery was found, which can be explained by psychological and individual factors, such as demotivation for ambulation, insecurity and fear of leaving the bed.

According to research conducted in individuals who underwent cardiac surgery in Australia, the more exercises are done during the physiotherapeutic sessions, the more independent mobility is observed [13]. The greater the mobility or independent physical activities during the hospitalization period, the better the long-term functional recovery and the more independence in phase II of the rehabilitation is shown. Besides all this, the mobility also reduces postoperative complications, and improves the physiological functional capacity and healing process. It also accelerates the discharge process, which is already associated with reduction of re-hospitalization $[12,13$, 24].

A limitation of this study was that psychological and individual factors were not evaluated. And these factors have not been assessed previously. However, they may be potential determinants of leaving the bed, as the high variability of the number of steps shown was not related to postoperative factors or level of previous physical activity. Along with the advances in surgical procedures and multi-professional care, it is up to physiotherapy to renew itself and to create new protocols to reduce immobility. Thus, in order to improve the cardiac rehabilitation phase $I$, it is suggested that new studies evaluate whether the increase in techniques in the ICU or a differentiated approach in the wards can modify this outcome.

\section{Conclusions}

Individuals with a longer stay in the intensive care unit, as well as female patients, have lower mobility in the ward. This mobility was not related to intra- and postoperative factors, but it is noteworthy that, although a great variation was shown, the number of steps increases during hospitalization. We suggest that news papers evaluate the physiological factors evolved after cardiac surgery, and if it can explain the reduce of mobility in a population without functional disorders.

\section{References}

[1] João, P. R. D., and Junior, F. F. 2003. "Cuidados Imediatos no Pós-operatório de Cirurgia Cardíaca." $J$ Pediatr Rio J [Internet] 79 (supl.2): S213-22.

[2] Soares, G. M. T., Ferreira, D. C. D. S., Gonçalves, M. P. C., Alves, T. G. de S. A., David, F.L., Henriques, K. M. de C., et al. 2011. "Prevalência das Principais Complicações Pós-Operatórias em Cirurgias Cardíacas." Rev Bras Cardiol. 24 (3): 139-46.

[3] Carvalho, T. G. De, Lucia, A., Silva, G., Santos, M. L., Schäfer, J., and Seve, L. 2013. "Relação Entre Saída Precoce do Leito na Unidade de Terapia Intensiva e Funcionalidade Pós-alta: um Estudo Piloto." Rev Epidemiol e Control da Infecção. 3 (3): 82-6.

[4] Guimarães, A. R., Melo, T. A. De, Frazão, M., and Gardenghi, G. 2015. "Alterações Fisiológicas da Caminhada e Tempo de Internamento no Pós-Operatório 
de Cirurgia Cardíaca.” Int J Cardiovasc Sci. 28 (5): 480-6.

[5] Rosa, C. S. da C., Messias, K. P., Fernandes, R. A., da Silva, C. B., Monteiro, H. L., and Freitas Junior, I. F. 2011. “Atividade Física Habitual de Crianças e Adolescentes Mensurada por Pedômetro e sua Relação com Índices Nutricionais.” Rev Bras Cineantropometria e Desempenho Hum. 13 (1): 22-8.

[6] Nyssen, S. M., dos Santos, J. G., Barusso, M. S., Junior, A. D. de O., Di Lorenzo, V. A. P., and Jamami, M. 2013. "Nível de Atividade Física e Preditores de Mortalidade na DPOC.” J Bras Pneumol. 39 (6): 659-66.

[7] Da Silva, C. F. F., Amorim, P. R. dos S., de Carvalho, C. J., de Faria, M. M., and Lima, L. M. 2015. “Associação de Força e Nível de Atividade Física à Densidade Mineral Óssea na pós Menopausa.” Rev Bras Med do Esporte. 21 (2): 117-21.

[8] de Oliveira, A. S., Santos, A. da C., Cabral, D. L., Brasileiro-Santos, M. do S., and Acelerômetros, Pedômetros, E. 2010. "Monitores De Freqüência Cardíaca São Adequados Para Avaliar O Nível De Atividade Física Em Idosos? Uma Revisão Sistemática.” Rev Bras Ciência e Mov [Internet]. 18 (2): 100-6.

[9] Organização, M. de S. 2004. "CIF: Classificação Internacional de Funcionalidade.” Calssificação Int Funcionalidade, Incapacidade e Saude [Internet]. 238.

[10] Lee, P. H., Macfarlane, D. J., Lam, T., and Stewart, S. M. 2011. "Validity of the International Physical Activity Questionnaire Short Form (IPAQ-SF): A Systematic Review.” Int J Behav Nutr Phys Act [Internet]. 8 (1): 115.

[11] Borges, L. J., Guidarini, F. C. S., Gerage, A. M., Scherer, F. C., Meurer, S. T., Borges, R. A., et al. 2014. "Pedômetros: Estratégia de Promoção da Atividade Física em Idosos.” Rev Bras Geriatr e Gerontol [Internet]. 211-3.

[12] Izawa, K. P., Watanabe, S., Hiraki, K., Morio, Y., Kasahara, Y., Takeichi, N., et al. 2012. "Determination of the Effectiveness of Accelerometer Use in the Promotion of Physical Activity in Cardiac Patients: A Randomized Controlled Trial.” Arch Phys Med Rehabil [Internet] 93 (11): 1896-902.

[13] Mungovan, S., Singh, P., Gass, G., Smart, N., and Hirschhorn, A. 2017. "Effect of Physical Activity in the First Five Days after Cardiac Surgery.” J Rehabil Med [Internet] 49 (1): 71-7.

[14] Nordon-Craft, A., Moss, M., Quan, D., and Schenkman, M. 2012. "Intensive Care Unit-Acquired Weakness: Implications for Physical Therapist Management.” Phys
Ther [Internet] 92 (12): 1494-506.

[15] De Jesus, F. S., De Macedo Paim, D., De Oliveira Brito, J., De Araujo Barros, I., Nogueira, T. B., Martinez, B. P., et al. 2016. "Mobility Decline in Patients Hospitalized in an Intensive Care Unit.” Rev Bras Ter Intensiva. 28 (2): 114-9.

[16] Borges, J. B. C., Ferreira, D. L. M. de P., Carvalho, S. M. R. de, Martins, A. S., Andrade, R. R., and Silva, M. A. de M. 2006. "Avaliação da Intensidade de dor e da Funcionalidade no Pós-operatório Recente de Cirurgia cardíaca.” Rev Bras Cir Cardiovasc [Internet] 21 (4): 393-402.

[17] Vollman, K. M. 2010. "Progressive Mobility in the Critically Ill.” Crit Care Nurse. 30 (2): 3-6.

[18] Maria, Y., Kawaguchi, F., Nawa, R. K., Figueiredo, T. B., Martins, L., and Pires-neto, R. C. 2016. "Perme Intensive Care Unit Mobility Score e ICU Mobility Scale: Tradução e Adaptação Cultural Para a Língua Portuguesa Falada no Brasil.” J Bras Pneumol. 42 (6): 429-34.

[19] Rosier, G. L., Ribeiro, A. M. R., Silva, S. O., Silva, S. O., and Lordello, G. G. G. 2017. "Revascularização Miocárdicao e Troca Valvar: Comparação no Perfil dos Indivíduos.” Rev. Saúde HIS 3 Dez (4): 46-50.

[20] Luiz, A., Cordeiro, L., Melo, T. A. De, Ávila, A., and Esquivel, M. S. 2015. "Influência da Deambulação Precoce no Tempo de Internação Hospitalar no Pós-operatório de Cirurgia Cardíaca.” Int J Cardiovasc Sci. 28 (5): 385-91.

[21] Dos Santos, F. K., Gomes, T. N. Q. F., de Souza, M. C., and Chaves, R. N. 2016. "Atividade Física, IMC e Risco Metabólico em Adolescentes Portugueses.” Rev Bras Cineantropometria e Desempenho Hum. 18 (1): 103-13.

[22] Papaspyros, S., Uppal, S., Khan, S. A., Paul, S., and O’Regan, D. J. 2008. “Analysis of Bedside Entertainment Services’ Effect on Post Cardiac Surgery Physical Activity: A Prospective, Randomised Clinical Trial.” Eur $J$ Cardio-thoracic Surg. 34 (5): 1022-6.

[23] Costa Junior, J. M. F., Almeida, K. da S., Santos, M. C. de S., Carneiro, S. R., and Torres, D. da C. 2015. “Avaliação Pedométrica em Pacientes no Pós-Operatório de Cirurgia de Revascularização do Miocárdio, Após Mobilização Precoce.” Rev Para Med. 29 (2): 45-50.

[24] Luiz, A., Cordeiro, L., Melo, T. A. De, Ávila, A., and Esquivel, M. S. 2015. "Influência da Deambulação Precoce no Tempo de Internação Hospitalar no Pós-Operatório de Cirurgia Cardíaca.” Int J Cardiovasc Sci. 28 (5): 385-91. 